\title{
Foreign Body Stone of the Ureter Originated from the Suture Thread: A Case Report
}

\author{
Murat Dursun ${ }^{1}$, Eyyup Danis², Alper Otunctemur², Emin Ozbek ${ }^{3}$ \\ ${ }^{1}$ Department of Urology, Bahcelievler State Hospital, Istanbul, Turkey; \\ ${ }^{2}$ Department of Urology, Okmeydani Training and Research Hospital, Istanbul, \\ Turkey; \\ ${ }^{3}$ Department of Urology, Ataturk Training and Research Hospital, Katip Celebi \\ University, Izmir, Turkey \\ Received August 20, 2014; Accepted November 18, 2014.
}

Key words: Foreign bodies - Sutures - Ureter - Stone

Abstract: Foreign bodies placed into the ureter are uncommon. Unintentionally placed nonabsorbable sutures may cause obstruction and stone formation. If not recognized, the patient may become symptomatic. We present a diagnosis of a rare case from Turkey, in which a ureter stone was formed by a nonabsorbable suture in a male patient with a previous laparotomy.

Mailing Address: Dr. Murat Dursun, Department of Urology, Bahcelievler State Hospital, 34180, Kocasinan Merkez, Bahcelievler, Istanbul, Turkey; Phone: +90 21249670 00; Fax: +90 21249670 00; e-mail:mrt_drsn@hotmail.com 


\section{Introduction}

Foreign-body stones in the renal tract are not rare; they have been described in association with fragments of a catheter, suture materials and a wide spectrum of foreign bodies like hair, needles, bullets, chalk and porcelain (Beduschi and Wolf, 1997). Suture materials are commonly used in urological surgery, especially for surfaces in direct contact with urine. Although absorbable suture materials are used for these operations, encrustations on suture material and formation of a stone limit the success of surgery. Additional surgical interventions may be necessary after the formation of those stones. Clinical observations report that all of the suture materials serve as a nucleus for the formation of stones (Kaminski et al., 1978; Evans et al., 1990). Monofilament nonabsorbable suture may be resistant to lithiasis so long as its surface remains intact (Yudofsky and Scott, 1969). However, in this case we report a man with ureteric stone formation around polypropylene suture. Misplaced sutures in the ureter are uncommon, but may pose a difficult surgical and medico-legal problem if not promptly discovered. We subsequently treated the stone around suture endoscopically.

\section{Case report}

A 56-year-old male underwent laparotomy caused by stab wound injury 20 years ago. He has no information about what was done during the laparotomy. Maybe, he was treated for ureter injury during the laparotomy. He says he was treated successfully and was discharged after the treatment. He has had no complaint till present. He was admitted to our clinic with left lumber pain, dysuria and hematuria. An ultrasound demonstrated left-sided hydronephrosis and a computerized tomography scan showed left-sided hydronephrosis and $1 \mathrm{~cm}$ calcule located in left ureter (Figure 1). An intravenous urogram (IVU) demonstrated hydronephrosis with delayed excretion on the mid-distal ureter. The patient has no comorbidity.

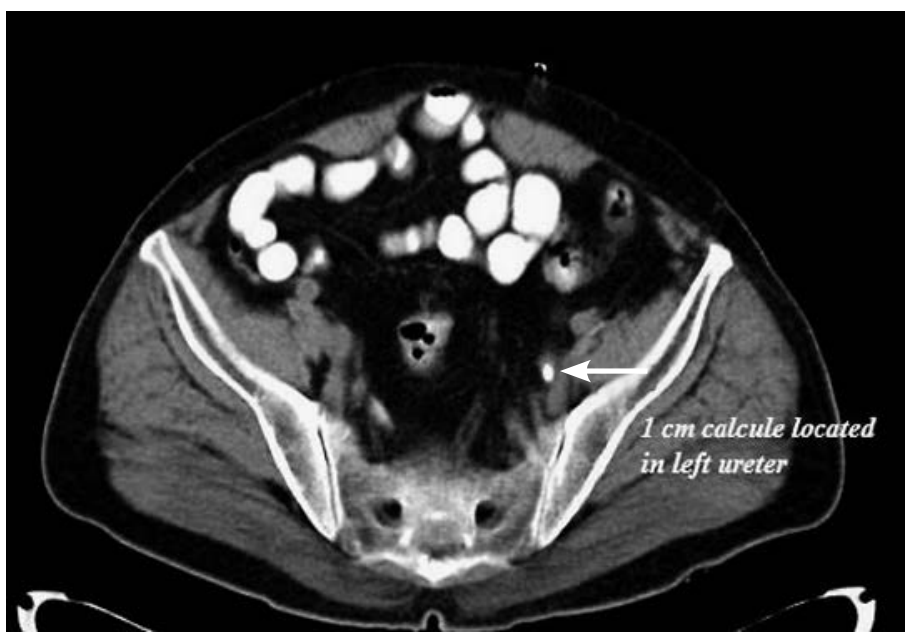

Figure $1-1 \mathrm{~cm}$ calcule located in the left ureter. 


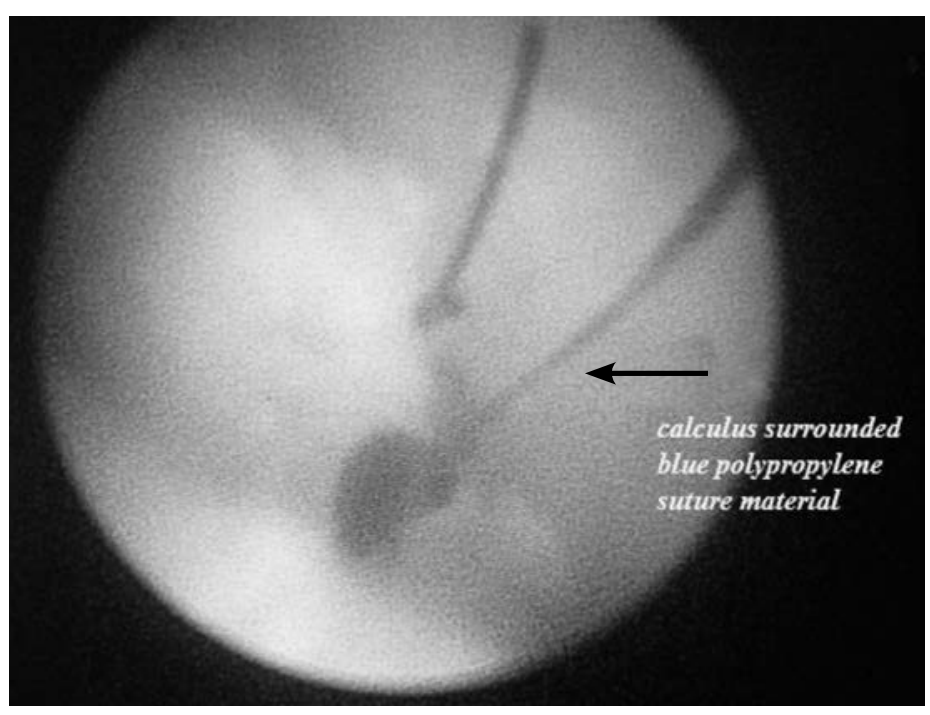

Figure $2-A$ ureteric stone formation surrounded polypropylene suture material.

The patient was treated with retrograde semirigid ureterorenoscopy. The left ureter was inspected using a $11 \mathrm{~F}$ semirigid ureteroscope (Storz). A stone adherent to the ureter wall was seen, and a holmium:YAG laser (Coherent) was used to fragment the stone $(0.5-1.2 \mathrm{~J} ; 5 \mathrm{~Hz})$. After a significant portion of the stone had been fragmented, it became apparent that the calculus surrounded polypropylene suture material in the ureter (Figure 2). We used Trice ${ }^{\circledR}$ three-pronged grasping forceps (Microvasive-Boston Scientific, Natick, MA) to extract the sutures.

\section{Discussion}

The presence of foreign bodies in the urinary tract has always been an interesting topic. Although foreign bodies in the body may remain asymptomatic for long periods, they may also cause various complications. In this case, the patient was admitted to our clinic 20 years after the operation. Suture material as a foreign body in the urinary tract was reported in previous studies (Lawrentschuk et al., 2004). Previous studies conducted on rats, rabbits and other animals tried to address this problem. A higher frequency of stone formation for polypropylene, which is a non-absorbable suture, was reported and this observation was explained in terms of longer duration of contact with urine (Stewart et al., 1990). Because foreign-body stone generation is related directly to the duration of urine contact, nonabsorbable suture is more prone to induce calculus formation. In this case, probably polypropylene suture was used 20 years ago for the treatment. Polypropylene is a plastic, synthetic suture that has low tissue reactivity and high tensile strength similar to nylon. Prolene can be purchased in a blue colour, which can be advantageous in localizing sutures in the scalp and dark-skinned individuals. Trevino et al. (1979) report a stone formation developing 1-2 years after a bladder 
surgery in which polypropylene was used. They hypothesize that this may be due the migration of non-absorbable suture from the tissue to the lumen with time.

Misplaced sutures may pose a difficult surgical and medico-legal problem if not promptly discovered. Open exploration is the most established means of removal. Endoscopic management of such situations has become feasible since the advent of laser technology and advanced ureteroscopic instrumentation. In this case, we chose to treat this patient with retrograde semirigid ureterorenoscopy. The advantage is that ureteroscopy has low complication rate, short expulsion time, and high stone-free rate after a single application with a high patient's satisfaction. Therefore, we believe that ureteroscopy should be the standard care for distal ureteral stones. A previous report described the use of laser to dissolve an intraluminal ureteric suture. The suture type was not stated, but Bagley et al. (1998) demonstrated in vitro that a holmium:YAG laser could dissolve all suture materials except goretex and that neodymium:YAG laser could dissolve all types of suture material. We also used holmium:YAG laser to dissolve suture material and we extract the sutures by Tricep ${ }^{\circledR}$ three-pronged grasping forceps. Ureteroscopic techniques for retrieving misplaced ureteric stents use triradiate forceps or baskets. These techniques are suited to free intraluminal objects and were not appropriate in this instance, as traction on the suture could damage the ureter. But, in this case the suture material was free in the ureter after the laser therapy and we extracted the sutures successfully. This case also demonstrates the effectiveness of uretero-renoscopy in the diagnosis and management of patient's harboring urinary-tract foreign bodies. Ureterorenoscopic management is a minimal invasive treatment method and is usually associated with lower morbidity (Kirac et al., 2014).

\section{References}

Bagley, D. H., Schultz, E., Conlin, M. J. (1998) Laser division of intraluminal sutures. J. Endourol. 12, 355-357.

Beduschi, R., Wolf, J. S. Jr. (1997) Fragment of a catheter as a foreign body in the kidney. Tech. Urol. 3, 222224.

Evans, J.W., Chapple, C. R., Ralph, D. J., Milroy, E. J. (1990) Bladder calculus formation as a complication of the Stamey procedure. Br.J. Urol. 65, 580-582.

Kaminski, J. M., Kats, A. R., Woodward, S. C. (1978) Urinary bladder calculus formation on sutures in rabbits, cats and dogs. Surg. Gynecol. Obstet. 146, 353-357.

Kirac, M., Atkin, M. S., Biri, H., Deniz, N. (2014) Ureteroscopy: the first-line treatment for distally located ureteral stones smaller than $10 \mathrm{~mm}$. Urol. J. 10(4), 1028-1034.

Lawrentschuk, N., Rogerson, J., Bolton, D. M. (2004) Use of holmium laser for removal of an intraluminal ureteric suture. Int. J. Urol. 11(10), 916-918.

Stewart, D.W., Buffington, P. J., Wacksman, J. (1990) Suture material in bladder surgery a comparison of polydioxanone, polyglactin and chromic catgut. J. Urol. 143, 1261-1263.

Trevino, R., Goldstein, A. M., Vartanian, N. L. (1979) Vesical bladder stones formed around non-absorbable sutures and possible explanation for their delayed appearance. J. Urol. 122, 849.

Yudofsky, S. C., Scott, F. B. (1969) Urolithiasis on suture materials: Its importance, pathogenesis and prophylaxis: an introduction to the monofilament Teflon suture. J. Urol. 102, 745-749.

Dursun M.; Danis E.; Otunctemur A.; Ozbek E. 